\title{
Environmental geoscience in Southeast Asia: Current trends and future challenges
}

Institute for Environment and Development (LESTARI), Universiti Kebangsaan Malaysia, 43600 Bangi, Selangor, Darul Ehsan, Malaysia.

\begin{abstract}
Southeast Asia is a high growth area, both from the population and development perspectives. As a result of rapid development, the region has been subjected to tremendous land use changes, hastening certain geological processes, which threaten human safety and the environment. In addition, human activity depending on limited resources such as land, soil, water and minerals has also adversely impacted the ecology of the region. The importance of environmental geoscience was brought to fore in Southeast Asia over the past two decades due to geological hazards. Other issues that presently require environmental geoscience inputs include resource and energy utilization, conservation of physical heritage, waste disposal as well as identification and cleanup of polluted land and water. Solutions to these problems require multidisciplinary inputs as well as new knowledge and approaches. Pilot initiatives that relate to integrated management of basins, watersheds and coastal zones, which involve scenario generation, are being undertaken in Malaysia, Thailand and Indonesia. These initiatives, based on remote sensing, have brought in a wealth of information to the region. However, on its own, such data cannot provide conclusive answers to ensure the integrity of the environment. There is an urgent need to fill knowledge and data gaps for improved management and decision-making in this region and environmental geoscience has an important contribution to make, in this context.
\end{abstract}

\section{Introduction}

Southeast Asia is a high growth area, both from the population and development perspectives. It is anticipated that by the year 2020 , Southeast Asia will have a population of $655,523,000$, compared to 516,401,000 in 1991 (ESCAP, 1999a). The present population density in this region varies from 22-6475 persons per square kilometer. About $38 \%$ of the total population reside in urban areas and this percentage is expected to increase dramatically in the coming years. In order to develop and improve the population's quality of life, the general approach in this region is to "grow now and clean up later". This approach has led to high environmental costs and efforts have been initiated to improve environmental management in the region.

The recent economic crisis in Southeast Asia has had both positive and negative implications on environmental management. Anticipated short-term reductions in urban air pollution from industrial sources and traffic have been one positive aspect of the economic crisis (World Bank, 1998). Notwithstanding this, urban air quality management will have to be improved, lest it reaches higher levels, which may further constrain economic growth. The economic crisis also offered several countries an opportunity to introduce environmental considerations into reformed development plans to ensure sustainable growth. On the negative side, contracting economic activity brought forth budget cuts in the region's environment and resource management agencies, which threaten to undermine progress in monitoring and enforcement capabilities. In some countries, the zest to recover from the economic crisis has resulted in relaxation of regulations related to certain environmental protection and pollution control measures. However, it is likely that the situation will improve considering the emerging signs of advancement in the economic front.

This paper briefly describes some of the environmental issues in Southeast Asia, and initiatives taken to manage them. The role of environmental geosciences in bridging crucial knowledge and data gaps for improved management and decision-making in this region is discussed in this context.

\section{Environmental issues in Southeast Asia}

Human activity depending on limited resources such as land, soil, water and minerals has adversely impacted the ecology of Southeast Asia. Thus, pollution and environmental degradation are major issues. Problems related to diminishing natural resources and occurrences of geological hazards are also prevalent in the region.

Land degradation due to soil erosion, soil salinization and intensification of agriculture continue unabated in Southeast Asia while the quality of air and water has also declined (ESCAP, 1999b). In addition, the population growth rate exceeds the rate of food production. Forests in this region are diminishing at a rate of $1.2 \%$ per year, where half of the losses have occurred in the past three decades. Forest and bush fires reached catastrophic dimensions during the 1997-1998 period, destroying millions of hectares of forest and causing damages worth about US\$ 4.5 billion (Ertuna, 1999). The fires, caused by clearing of forests for agriculture and re-plantation activities, were compounded by drought conditions due to the El Nino phenomenon. The fires created a blanket of haze that covered the region, creating health problems, causing accidents and disrupting land, sea and air transportation systems. In 1990, the health cost related to air pollution by particulates and lead contributed to a loss of $2 \%$ of the GNP in Thailand, and between $0.8-3.3 \%$ for Indonesia and the Philippines (ESCAP, 1999b). The health cost that related to the haze episode of 1997-1998 was most likely higher.

Deforestation coupled with unsustainable forest management and agricultural practices contribute to extremely high levels of suspended particulates in the rivers of Southeast Asia. The increasing level of population is not supported by appropriate infrastructure for wastewater treatment. For instance, only $15 \%$ of wastewater is treated in Manila (ESCAP, 1999b). As a result of this weakness, organic waste and fecal coliform levels in this region are about twice the world's average. In addition to water pollution, the amount of waste generated in this region is also rising rapidly. Growth and affluence had brought about an increase in domestic waste. About $50-70 \%$ of local government revenues is spent on waste management and yet, the collection services are weak in many countries 
Table 1 The types and intensity of earthquakes (EQ), tsunamis $(T S)$, volcanic eruptions (VOL), flood (FL), drought (DR) and landslides (LS) reported in selected countries of Southeast Asia. (Source: Whitehouse, 1999)

\begin{tabular}{|l|c|c|c|c|c|c|}
\hline Country & EQ & TS & VOL & FL & DR & LS \\
\hline Indonesia & S & L & M & M & M & L \\
\hline Lao PDR & - & - & - & M & L & - \\
\hline Malaysia & & L & & S & S & L \\
\hline Myanmar & - & - & - & M & M & M \\
\hline Philippines & S & L & M & S & L & S \\
\hline Thailand & L & - & - & S & S & L \\
\hline Vietnam & L & L & - & S & L & S \\
\hline
\end{tabular}

(ESCAP, 1999b). Hazardous and toxic waste are also of particular concern in the region due to the rise of new petrochemical industries.

Southeast Asia has suffered great losses from natural and human-induced geological disasters. Human-induced geological disasters occur when certain geological processes are hastened as a result of rapid development. In terms of losses, the total cost and number of deaths are much higher when disasters occur in the urban areas (Whitehouse, 1999). The amount of losses due to disasters has been increasing over the years (ESCAP, 1999c). This increase is attributed to the growing population and higher building density in urban areas. The focus of development in areas prone to hazards, without the appropriate protective and maintenance measures, also contributes to the increasing losses due to disasters. In addition, the damage caused by hazards is higher in countries where environmental degradation is uncontrolled. Deforestation, erosion, overgrazing, overcultivation and incorrect agricultural practices as well as the degradation of natural protection increase the impacts of natural hazards. Among the hazards experienced in the region include earthquakes, volcanic eruptions, tsunamis, landslide, subsidence, flood and drought. The type of disaster and its intensity vary from country to country (Table 1).

Earthquakes, volcanic eruptions and tsunamis have caused the highest number of casualties and property destruction in the region. Countries vulnerable to earthquake and tsunamis in Southeast Asia are the Philippines, Indonesia and Vietnam (ESCAP, 1999c). The most destructive earthquake reported in the recent history of the Philippines occurred in 1992. It claimed 1666 lives, injured 3,561 and caused damage worth US\$ 1 billion. In 1992, about 2,000 lives were lost and 90,000 people were rendered homeless in Indonesia when an earthquake was followed by tsunamis. This was only one of the several incidences of earthquakes and tsunamis in the country. The most seismically active area in Vietnam is the Red River Delta, where the capital city of Hanoi, major infrastructure projects and almost $50 \%$ of the population are located. At least 500 earthquakes have been recorded in the area, making this area highly vulnerable to disasters unless appropriate measures are taken. In Southeast Asia, only Indonesia and the Philippines are frequently subject to severe volcanic eruptions (ESCAP, 1999c). There are 129 active volcanoes in Indonesia and in the past 200 years, about 175,000 lives have been lost due to eruptions and associated tsunamis. In comparison, only 21 volcanoes are considered active in the Philippines. The Mount Pinatubo volcanic eruption was the worst disaster in the recent history of the Philippines. The eruption killed 847 people and caused damages of about US\$ 100 billion to the infrastructure.

Landslides have been reported in Malaysia, Thailand, Myanmar, Vietnam and the Philippines (ESCAP, 1999c). The most severe incident in Malaysia killed about 48 people while a serious landslide in Thailand resulted in about 400 deaths. The landslide occurrences are no less destructive in the other countries. Several cities in the region are built on river deltas and coastal plains underlain by aquifers and rely on groundwater for their water supply. Extensive groundwater withdrawal has resulted in land subsidence and salination of groundwater in cities such as Bangkok and Jakarta, threatening the water supply and safety of urban dwellers. Extreme floods devastated Vietnam in 1998, where the dykes that provided protection were breached by floodwaters (ESCAP 1999c). Floods and flash-floods have also been reported in several other countries in the region. Severe drought conditions occurred in many parts of Southeast Asia due to the El Nino phenomenon (Ertuna 1999). The drought resulted in severe water shortages in countries such as Malaysia, Indonesia and the Philippines. The water shortage problem was compounded by contamination of rivers, which are the main source of water supply in the region.

\section{Challenges for environmental geoscience}

Solutions to environmental problems and the implementation of sustainable development require multidisciplinary inputs as well as new knowledge and approaches. Pilot initiatives that require holistic approaches are being conducted in several countries in the region. Among these include the development of strategies to operationalise sustainable development, integrated management of basins and watersheds, which involve scenario generation, as well as water resources and geological hazard management.

The promotion of sustainable development is a major concern for many countries in Southeast Asia. Several countries have already implemented national Agenda 21 initiatives and more are expected to follow suit. In Malaysia for instance, the national Agenda 21 initiative is being translated into a State Agenda 21 project, which will subsequently be implemented at the local level. The successful implementation of Agenda 21 requires the participation of all stakeholders, and the Malaysian experience has revealed that geosciences have a significant contribution to make. This includes aspects related to mineral resource and energy utilization, conservation of physical heritage, selection of waste disposal sites as well as identification and cleanup of polluted land. An important means of incorporating sustainability into planning for national development involves the identification and establishment of indicators. Indicators provide a means of describing trends, setting targets and assessing the effectiveness of achieving these targets. To assess sustainability in development, measures of environmental quality, social and economic aspects as well as their inter-linkages need to be identified (Peterson et al., 1999). In addition to several national projects, a regional project to develop indicators for sustainable development was also initiated in response to Agenda 21 (ESCAP, 1997). Unfortunately, in many of the indicator projects world-wide, measures of environmental quality only take into account the contribution of human actions (Berger, 1997). The contribution of natural processes and their linkages to the environment, social and economic dimensions tend to be ignored. This contribution can be taken into account through the identification of relevant geoindicators. The Malaysian government has initiated a pilot study to identify suitable geoindicators and address this gap, to support its national initiative on the development of indicators for sustainable development. The role of environmental geosciences is crucial in this project, which is funded by the Malaysian Government through its Intensification of Research in Priority Areas mechanism.

A basin-wide holistic pilot study on ecosystem health was conducted in the Langat Basin, Malaysia. This study, the first of its kind in Asia, was carried out under the auspices of the United Nations Environment Program through its Regional Office in Bangkok, and funded by the Danish Cooperation on Environment and Development (DANCED). The objective of study was to determine the health status of the Langat Basin ecosystem through the use of a suite of indicators. The study covers several disciplines including environmental health, biodiversity, water pollution, social well being as well as population and economic growth (Nordin et al., 1999). Gaps pertaining to ecosystem health assessment with respect to geohazard occurrences and mineral resources were also addressed. The pilot study has resulted in the development of an ecosystem scenario generation tool, based on the ecosystem health 
framework. This tool will be able to assist decision-making with respect to environment and development within the Basin. Several other initiatives have been carried out in the region with respect to basin-wide studies, but these are sectoral and clearly lack geoscience inputs. One such initiative is the baseline assessment of forest cover in the Lower Mekong Basin, utilizing remote sensing and GIS technologies, funded by the German Technical Cooperation. Other initiatives include a forest hydrology project in Western Ghat, India and case studies on landuse and cover change in Malaysia, Indonesia, the Philippines and Thailand (LUCC, 1998). The purpose of the landuse and cover change study was to identify driving forces of landuse change to develop a dynamic model for monitoring and prediction of future trends of change. The physical input for this study was mainly from geographers and very little environmental geoscience information was utilized.

The humid tropical rainbelt of Southeast Asia has recently experienced severe water shortage, and increasing pollution of surface and groundwater threatens to make the situation worse. This has generated awareness for the creation of a new dimension in water resources planning and management. The most urgent hydrological and water resource management problems require integrated environmental and socio-cultural solutions. This is recognized by the International Hydrological Program, which is now in its fifth phase of conducting applied research and education in the field of hydrology and water management. In its sixth phase (2002-2007), the emphasis for Asia is on the development of more holistic, integrated approaches (IHP, 1998). Many of the activities proposed, particularly those related to water resources assessment and management in humid megacities, as well as the development of decision support systems, would require environmental geoscience inputs. The Economic and Social Commission for Asia and the Pacific (ESCAP) has also initiated a program on integrated development and management of water resources in the region. In addition to this, national projects on exploration for groundwater is anticipated to increase, to support growing urban centers, particularly in Malaysia, Thailand and Indonesia. In the case of water resources, geosciences clearly have a vital role to play in ensuring societal well-being.

With respect to geohazards, there are several international programs in Asia promoting the use of remote sensing and GIS as a tool for formulating prediction and mitigating measures. In addition, national initiatives utilizing similar tools are also being undertaken, led by geological surveys and equivalent organizations in several countries such as Malaysia, Thailand, Indonesia and the Philippines. In such countries GIS is increasingly becoming a very important tool to manage, retrieve and present geological information. Despite these efforts, there is still much room for improvement in the region. From the sectoral perspective, improvements are required in the quality of forecasts and warnings to natural hazards (ESCAP, 1999c). Furthermore, hazard mapping and risk assessment for disaster prone areas as well as monitoring of such areas need to be increased. Besides this, in certain countries such as Laos and Vietnam, the availability of relevant information is still lacking and the production of urban geological atlases are a priority. From the crosssectoral perspective, it is noted that the integration of geohazards management within the urban landuse planning framework is disregarded. This aspect needs to be looked into based on country specific studies. Initiatives are already underway in Malaysia, instituted by environmental geologists in the country (Pereira and Komoo, 1998).

\section{Concluding remarks}

The importance of environmental geoscience was brought to fore in Southeast Asia over the past two decades due to geological disasters. Problems associated with earthquakes, tsunamis, volcanic eruptions, landslide, subsidence, and floods are among the hazards common to all countries of this region, particularly in densely populated areas where natural conditions are made worse by human intervention. Other issues that presently require environmental geoscience inputs are related to ensuring the sustainability of development and envi- ronment in the region. Among these are mineral resource and energy utilization, conservation of physical heritage, waste disposal as well as identification and cleanup of polluted land and water. The current initiatives, particularly those based on remote sensing and GIS techniques, have brought in a wealth of geological information to some countries in the region. On its own, such data cannot provide conclusive answers to ensure the integrity and sustainability of the environment. Much work needs to be done to integrate this information into the various tools and approaches that are being developed to strengthen policy and decision-making. In some countries, there is an urgent need to fill knowledge and data gaps for improved management and decision-making and environmental geoscience has an important contribution to make, in this context.

\section{Acknowledgement}

This paper is part of the research funded by IRPA 08-02-02-0040. The support of Prof. Ibrahim Komoo of the Institute for Environment and Development (LESTARI), Universiti Kebangsaan Malaysia, during the preparation of this paper is gratefully acknowledged.

\section{References}

Berger, A.R. 1997. Natural environment change: A challenge to the DSR approach. SCOPE 58, 191-197.

Ertuna, C. 1999. Overview of experiences and responses to recent disasters in Asia. IDNDR-ESCAP Regional Meeting for Asia: Risk reduction \& society in the 21st century, Bangkok, 23-26 February 1999.

ESCAP 1997. Towards indicators of sustainable development in Asia and the Pacific. Economic and Social Commission for Asia and the Pacific. United Nations, New York.

ESCAP 1999a. 1999 ESCAP Population Data Sheet. http://unescap.org/pop/ data_sheet/1999_tab5_main.htm (15 February 1999).

ESCAP 1999b. Background on Ministerial Conference on Environment and Development in Asia and the Pacific 2000. At: http://unescap.org/enrd/ environ/mced/background.html .(20 December 1999)

ESCAP 1999c. Geology-related hazards, resources and management for disaster reduction in Asia. IDNDR-ESCAP Regional meeting for Asia: Risk reduction \& society in the 21st century, Bangkok, 23-26 February 1999.

IHP 1998. International Hydrological Programme, IHP VI (2002-2007) Water interactions: Systems at risk and social challenges. http://www.pangea.org/ orgs/unesco/Publicatios/ihp6.html\#t3f32

LUCC 1998. LUCC case studies in Southeast Asia. http://www.start.or.th/LUCC/aboutluc.htm\#lucc_in_southeast_asia.gif

Nordin, M., Pereira, J.J., A. Fariz, Saiful Arif Abdullah, Ibrahim Komoo Shahruddin Idrus, Pauzi Abdullah, Abdul Hadi Harman Shah, Abullah Samat, Rospidah Ghazali, W. Mohd Muhiyuddin and Muhammad Abu Yusuf 1999. Ecosystem health in Malaysia: A case study of the Langat Basin. Paper for the International Congress on Ecosystem Health-Managing for Ecosystem Health. Organisers: University of California \& International Society for Ecosystem Health, Sacramento, California: 15-20 August 1999.

Joy Jacqueline Pereira is a Research Fellow at the Institute for Environment and Development (LESTARI) and heads the programme on Sustainable Urban Ecosystems. She has worked in the field of environmental geoscience, in support of policy research on sustainable development since 1995. Her current research projects are on the application of geoindicators for sustainable urban development, management of urban geohazards, urban geological heritage, ecosystem health, mineral flows and implementation of Agenda 21.

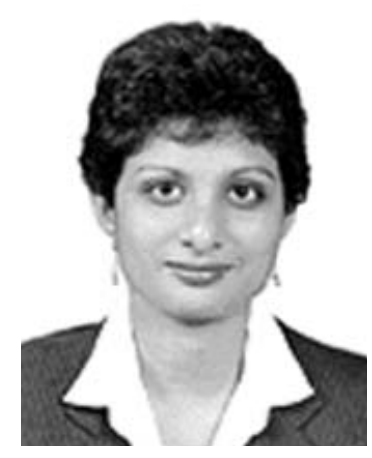

